\title{
PREVENÇÃO DE PERDAS NO VAREJO SUPERMERCADISTA
}

\section{PREVENTION OF LOSSES IN THE SUPERMARKET RETAIL}

Recebimento: 01/08/2017- Aceite: 05/11/2017- Publicação: 23/12/2017

Processo de Avaliação: Double Blind Review

Nardo Gonçalves dos Santos ${ }^{1}$

Mestre em Administração de Empresas pelo Centro Universitário das Faculdades

Metropolitanas Unidas- FMU

nardosan@gmail.com

Celso Machado Júnior

Professor Doutor do Programa Stricto Sensu Mestrado do Centro Universitário das

Faculdades Metropolitanas Unidas - FMU

celsomachado1@gmail.com

Roberto Bazanini

Doutor em Comunicação e Semiótica pela Pontifícia Universidade Católica de São PauloPUCSP

Pós-Doutorado em Comunicação e Cultura pela Universidade Paulista - UNIP

Professor da Universidade Paulista - UNIP

roberto.bazanini@terra.com.br

Daielly Melina Nassif Mantovani

Professora Doutora do Programa de Pós-graduação em Administração (PPGA-FMU)e do Programa de Pós-Graduação em Governança Corporativa (MPGC-FMU) no Centro Universitário das Faculdades Metropolitanas Unidas- FMU

daimantovani@gmail.com

Claudia Cristiane Cruzato Yoshimura

Mestranda em Administração de Empresas - Governança Corporativa, pelo Centro Universitário das Faculdades Metropolitanas Unidas- FMU

claudia.yoshimura@fmu.br

Rony Roberto Aurélio

Mestranda em Administração de Empresas - Governança Corporativa, pelo Centro Universitário das Faculdades Metropolitanas Unidas - FMU

aurelio.2000@hotmail.com

\footnotetext{
${ }^{1}$ Autor para correspondência: Centro Universitário das Faculdades Metropolitanas Unidas- FMU- Rua Vergueiro, 107- Liberdade- CEP 01504-001 - São Paulo - SP Brasil.
}

Revista ENIAC Pesquisa, Guarulhos (SP), V.6, n.2, jun.- dez. 2017 


\section{RESUMO}

A presente pesquisa apresenta como objetivo identificar as práticas de prevenção de perdas no setor de varejo supermercadista. Trata-se de uma pesquisa qualitativa apoiada em um estudo de caso único por se tratar de apenas uma empresa, mas que, no entanto, analisa diferentes lojas da rede. A empresa pesquisada atua no setor de varejo supermercadista de grande porte com atuação nacional. As práticas de prevenção de perdas apresentam, em grande parte, sinergia potencializando assim os resultados positivos. Como práticas de gestão de Prevenção de Perdas identificou-se uma estrutura organizacional voltada a esta atividade, com um processo de comunicação entre a alta gestão e o nível operacional da loja, entre as diferentes unidades da organização. Utiliza-se procedimentos e protocolos, que abordam metas de desempenho, destinados a realização da atividade de prevenção de perdas, uniformizando assim as ações de todos os envolvidos. O continuo treinamento e um sistema informatizado de prevenção de perdas asseguram a acuidade da gestão.

PALAVRAS-CHAVE: Praticas de prevenção de perdas; Gestão de riscos; Governança corporativa.

\section{ABSTRACT}

The present research aims to identify loss prevention practices in the supermarket retail sector. It is a qualitative research supported by a single case study, but nevertheless analyzes different stores in the network. The researched company operates in the large supermarket retail sector with national performance. Loss prevention practices have, to a large extent, synergy, thus enhancing positive results. Loss Prevention management practices identified an organizational structure focused on this activity, with a process of communication between the top management and the operational level of the store, between the different units of the organization. Procedures and protocols, which address performance targets, are used to carry out the loss prevention activity, thus standardizing the actions of all those involved. Continuous training and a computerized loss prevention system ensure the accuracy of management.

KEYWORDS: Practices of Loss Prevention; Risk management; Corporate governance.

\section{INTRODUÇÃO}

Os grandes varejistas brasileiros buscam adquirir técnicas, tecnologia, ferramental e processos para prevenir perdas, desde o surgimento do conceito de Prevenção de Perdas que surgiu no Brasil na última década do século 20. De acordo com Santos (2007) até o início dos anos 90, mais especificamente na implantação do plano Real, o segmento de varejo brasileiro estabelecia maior foco de atenção nos rendimentos financeiros. Pois segundo o autor, as aplicações financeiras representavam a principal fonte de lucro do setor, em função das taxas de retorno da época. Os varejistas se apoiavam no parcelamento elástico e de longo prazo na aquisição de mercadorias se seus fornecedores, se contrapondo as vendas à vista aos clientes finais. Esta dinâmica possibilitava aos varejistas receber pela venda do produto, antes de realizar o seu pagamento, e neste intervalo de tempo, realizar a aplicação financeira destes recursos. Entretanto, após a estabilização da moeda, esse ciclo chegou ao fim e os varejistas se voltaram para a geração de lucros, a partir da eficiência e eficácia das operações, dedicando-

Revista ENIAC Pesquisa, Guarulhos (SP), V.6, n.2, jun.- dez. 2017 
se a redução de despesas. Simultaneamente, o segmento vivenciou acirrada competitividade, que resultou em margens de lucro cada vez menores (SANTOS, 2007).

Este contexto demandou das empresas varejistas maior atenção e empenho com: a gestão administrativa, os processos realizados, os colaboradores e com o mix de produtos comercializados. Esta abordagem desenvolveu nos varejistas a busca da efetividade do negócio, estabelecendo atenção com as perdas que ocorrem durante todo o processo de comercialização dos produtos. Destaca-se que as Lojas Americanas se posicionam como a primeira empresa brasileira a criar um departamento de Prevenção, posicionando-se assim como a pioneira nesta atividade. O desempenho positivo observado pela empresa resultou em melhoras significativas no desempenho financeiro. Moura (2014) lembra que o processo de desenvolvimento da Prevenção de Perdas no varejo brasileiro pode ser separado em duas fases. A primeira marcada pela falta de conhecimento dos varejistas. Condição esta que motivou o Programa de Administração de Varejo - PROVAR e o Instituto Brasileiro de Executivos de Varejo e Mercado de Consumo - IBEVAR a formar grupos de estudo, e a realizar fóruns destinados a troca de informações e experiências entre varejistas e a desenvolver benchmarking com as boas práticas das empresas varejistas americanas.

O setor varejista, que se destina a venda de produtos em pequenas quantidades, consolidou o entendimento da necessidade de estabelecer o baseline da Prevenção de Perdas. O baseline se caracteriza como os requisitos mínimos que o setor de varejo deve exercer em relação a: Processos, Pessoas, Controles e Tecnologia. Numa primeira etapa houve a implantação de controles e indicadores para monitoramento das perdas. Como resultado observou-se um significativo aumento das perdas. Moura (2014) aponta que este aumento no volume de perdas, estava relacionado ao fato de se controlar algo que não era anteriormente analisado, assim o processo possibilitou identificar perdas que eram de total desconhecimento dos varejistas. $\mathrm{O}$ autor aponta que a etapa subsequente foi marcada pela correta identificação dos fatores geradores de perdas e o desenvolvimento de estratégias adequadas à mitigação, eliminação ou administração dessas perdas. Assim, o nível de maturidade de muitas empresas na gestão das perdas atingiu um patamar profissional e as perdas chegaram a um estágio residual.

Frente a este contexto a presente pesquisa apresenta como objetivo identificar as práticas de prevenção de perdas no setor de varejo supermercadista. A pesquisa se desenvolve na área operacional de unidades de uma empresa que atua no setor Supermercadista. Além deste capitulo introdutório, a pesquisa apresenta o referencial teórico, a metodologia empregada, a análise dos dados, a discussão, encerrando com as considerações finais.

\section{REFERNCIAL TEÓRICO}

Segundo Santos (2007) o conceito de perdas diz respeito a fatos geradores de resultados desfavoráveis às atividades empresariais com consequente redução dos lucros ou até mesmo a geração de prejuízos. Não obstante, a Prevenção de Perdas surge como a ferramenta administrativa que demanda investimentos em recursos humanos e tecnológicos para seu devido controle.

De acordo com Moura (2014) a Prevenção de Perdas surge das necessidades de encontrar respostas aos riscos aos quais a empresa está exposta, e entre esses riscos, destacase o risco operacional. Segundo Bergamini Júnior (2005) o risco operacional se consolida nas fraudes praticadas por funcionários ou terceiros e/ou em falhas nos processos de negócio e sistemas de informação. Ocorre geralmente em função da inadequação do desenho

Revista ENIAC Pesquisa, Guarulhos (SP), V.6, n.2, jun.- dez. 2017 
organizacional da empresa, da falta de planejamento, monitoração e delegação de atribuições e autoridade, da falta de padronização e/ou uniformidade de processos.

O risco operacional é resultado da realização das operações da empresa, e está associado às deficiências nos controles internos (BANCO CENTRAL, 2006). O Comitê da Basiléia sobre Supervisão Bancária por meio do Bank for International Settlements (BIS, 2004, p. 12) afirma que “(...) o risco operacional é definido como o risco de perda resultante de processos internos, sistemas inadequados, eventos externos e pessoas. Essa definição inclui o risco jurídico, porém exclui o estratégico e de reputação". Hahn e Kuhn (2012) pactuam com a definição do Banco Central (2006) sobre risco operacional, afirmando que esses eventos se relacionam às perdas ocasionadas por: i) eventos inadequados ou deficientes; ii) incorreção nos controles internos, geralmente relacionado as pessoas; iii) ferramentas, métodos, procedimentos e sistemas de controle que possibilitam problemas operacionais. Assim, os inúmeros potenciais riscos de uma corporação são decorrentes de processos ou controles ineficazes criando um cenário propicio à ocorrência de fraudes e deslizes praticados por colaboradores e agentes externos. A falta de padronização de procedimentos é outro fator que corrobora para o insucesso da execução da estratégia corporativa e o alcance de metas, dando grande fomento ao risco operacional (TEIXEIRA NETO; ARAÚJO, 2007).

Há fatores relacionados a maneira como a administração fará o gerenciamento de risco operacional. Destaca-se fatores como: grau de informatização do sistema, tecnologia utilizada, e complexidade das atividades. Segundo Longo (2009) os funcionários de uma organização são responsáveis por severas perdas devido a erros resultantes de incompetência, más decisões ou a falta de cumprimento das regras. Para o autor, o fato de o risco operacional ser parte de qualquer atividade, o posiciona como difícil de ser totalmente mitigado, no entanto, o aumento da conscientização dos envolvidos contribui para a diminuição da exposição da organização ao risco. O Quadro 1 apresenta a categorização de eventos de risco operacional, e as ações envolvidas.

\section{Quadro 1 - Categorização de eventos de risco operacional}

\begin{tabular}{|l|l|}
\hline \multicolumn{1}{|c|}{ Evento } & \multicolumn{1}{c|}{ Ações } \\
\hline Clientes, produtos e práticas de negócio & $\begin{array}{l}\text { Manipulação de mercado, práticas anticoncorrenciais quebra de } \\
\text { contrato. }\end{array}$ \\
\hline Danos a ativos físicos & Desastres naturais, terrorismo, vandalismo. \\
\hline Interrupção dos negócios e falha do sistema & Interrupção de operação, falha de software e hardware. \\
\hline Execução de processos e gestão & Erro nos dados de entrada, erro de contabilidade, negligência. \\
\hline Fraude interna & Roubo de bens, sonegação fiscal, corrupção, fraude contábil. \\
\hline Fraude externa & $\begin{array}{l}\text { Roubo de informações confidenciais, ataques de hackers, } \\
\text { falsificação de documentos. }\end{array}$ \\
\hline Práticas de emprego e segurança & Segregação, assédio, práticas ilegais. \\
\hline
\end{tabular}

Fonte: Adaptado de Longo (2009)

A Segurança Empresarial, segundo Moura (2014), está relacionada a um programa preventivo com a missão de proteger os valores da empresa, e preservar as condições operacionais dentro da normalidade, frente a possíveis ameaças e/ou situações de risco. Para o autor um plano de Segurança Patrimonial, apoiado por um Código de conduta Profissional deve embasar medidas a serem executadas em caso de ocorrência ou efetivação das ameaças provenientes do ambiente mitigando impactos causados aos ativos da empresa. O mesmo autor postula que em face aos obstáculos impostos pelo mercado, a Prevenção de Perdas se posiciona como importante ferramenta destinada a reduzir as perdas físicas. E que, um 
eficiente programa de gestão dos recursos nos processos desenvolvidos no piso de loja, melhoram os resultados da dos centros de distribuição e armazéns. $\mathrm{O}$ autor alerta que praticar ações que visem o aumento de vendas e ganhos de margem sem as devidas preocupações com as perdas, pode se mostrar um grande desperdício de esforços e investimentos importantes. Assim, grande parte dos varejistas de médio e grande dispõem de uma área de Prevenção de Perdas estruturada com foco no gerenciamento de riscos.

O termo "Prevenção de Perdas" surgiu no Brasil na última década do século 20. Desde então, os grandes varejistas nacionais vêm buscando adquirir técnicas, tecnologia, ferramentas e processos para prevenir perdas. Moura (2014) destaca que, o processo de desenvolvimento da Prevenção de Perdas no varejo brasileiro pode ser separado em duas fases. A primeira foi marcada pela falta de conhecimento dos varejistas. Isso motivou o PROVAR e IBEVAR a formarem grupos de estudo e realizarem fóruns para promoverem troca de informações e experiências entre varejistas e realizarem benchmarking com as boas práticas americanas. Esses fóruns auxiliaram o engajamento da alta direção no tema, e o início da formação de uma cultura de prevenção de perdas no setor. Moura (2014) indica que este movimento auxilio na formação do consenso da necessidade de se estabelecer o baseline da Prevenção de Perdas, composto pelas variáveis: Processos, Pessoas, Controles e Tecnologia. No início do processo observou-se, por parte das empresas, se identificava o aumento do desperdício em relação a períodos anteriores. Este aumento de desperdiçio observado estava relacionado ao fato de se controlar fatores antes não ponderados. A fase subsequente foi caracterizada pela identificação dos fatores geradores de perdas, e o desenvolvimento de estratégias adequadas à mitigação, eliminação ou administração dessas perdas. O nível de maturidade de muitas empresas nessa área atingiu um patamar satisfatório com perdas relacionada a apenas um estágio residual. (MOURA, 2014).

Vieira et al. (2010) aponta que o estoque é um dos principais ativos de uma empresa de varejo. Este ativo tangível pode se transformar em venda quando utilizado como insumo ou se comprado diretamente pelo cliente. $\mathrm{O}$ estoque é um recurso suscetível ao ambiente, e desta forma sujeito a danos ou subtração. Nesse sentido, o autor define perdas de mercadoria como as despesas provenientes da falta de controles eficientes dos estoques de mercadorias e sua consequente baixa como despesas para o resultado da empresa. Assim, um ativo comprado e incorporado ao estoque da companhia, caso deixe de ser vendido, por se danificar, ou por furto, avaria ou obsolescência, o mesmo é denominado com perda. Neste contexto, a Prevenção de Perdas é a área incumbida pela gestão e monitoramento das atividades e processos provedores de perdas físicas, perdas nas financeiras, quebras operacionais e rupturas.

Gomes, González Júnior e Lorett (2010) acrescentam o conceito indicando que perdas são ocorrências que necessariamente reduzem os lucros provenientes da operação da loja. Esses autores apontam como as mais expressivas categorias de perdas estão agrupadas nas categorias: operacionais e financeiras. As perdas financeiras têm sua origem nos furtos interno e externos, enquanto que as perdas operacionais são provenientes de danos causados por manuseio inadequado de mercadorias produção e compra de volumes excedentes à demanda, má gestão da manutenção de preços, controle de recebimento falho. Aspectos estes que podem ser classificados como mal gerenciamento operacional. A Prevenção de Perdas exige planejamento estratégico de longo prazo, e participação de todos os atores da empresa. A Prevenção de Perdas deve ser interpretada como uma área multidisciplinar, demandando assim a atenção e o envolvimento de todos os atores. (GOMES; GONZÁLEZ JÚNIOR; LORETT, 2010).

Revista ENIAC Pesquisa, Guarulhos (SP), V.6, n.2, jun.- dez. 2017 
De acordo com Piotto, Fávero e Angelo (2004), a preocupação com as perdas vem se tornando um item de atenção nas empresas varejistas, em especial no segmento supermercadista, uma vez que a sua redução pode representar ganhos significativos nas margens, posicionando-se assim como uma atitude empresarial em estratégia. Para Merlo, Ceribeli e Prado (2011) a interpretação de que o varejo brasileiro aumenta a sua atenção as questões de perdas, resulta a incorporação deste item no seu planejamento estratégico. Cabe salientar que a boa governança das perdas pode projetar ganhos expressivos no resultado final. Os autores lembram ainda que essa crescente preocupação com a prevenção de perdas se deve aos seguintes fatores: a) redução das margens de lucros em função da concorrência; b) economia bastante instável; c) mudança de comportamento dos empresários passando a atuar de uma forma reativa para forma preventiva.

Para a Associação Brasileira de Supermercados (ABRAS), em um mercado onde a disputa por participação é muito acirrada, em um cenário em que pequenas vantagens operacionais permitem alcançar expressivas vantagens competitivas, os índices de perda do varejo passaram a fazer parte do centro das discussões de grande parte de executivos e empreendedores do setor, que ainda encontram grandes dificuldades para identificar, medir e gerenciar os impactos maléficos nos resultados finais de seus negócios (ABRAS, 2015). Segundo Santos (2007), a prevenção de perdas passou a ser tratada como metodologia e área de trabalho vital para o resultado da empresa. Um número significativo de varejistas de grande porte definiu em seu organograma, a prevenção de perdas com posição de destaque na alta gestão, sendo que em alguns casos, status de diretoria e vice-presidência.

Dada à importância que o setor varejista representa na economia, e considerando as vulnerabilidades que envolvem a cadeia produtiva e operacional, esforços começaram a ser direcionados no sentido de gerir riscos e prevenir perdas. De acordo com a ABRAS (2015), as perdas no varejo em 2014, sobre o faturamento líquido, foram de $2,93 \%$, contra $2,52 \%$ em 2013, o que representa um percentual significativo, considerando as margens médias praticadas no setor, em especial no segmento supermercadista, que ficam abaixo dos dois dígitos.

No segmento supermercadista, quando separados por formato de varejo, observa-se que $100 \%$ dos hipermercados possuem área de prevenção estruturada, enquanto que os pequenos supermercados (com até $300 \mathrm{~m}^{2}$ ), apenas $39 \%$ possuem, o atacarejo responde com $65 \%$ e os supermercados acima de $300 \mathrm{~m}^{2} 58 \%$ (ABRAS, 2015). A ABRAS conclui que ainda há uma grande necessidade dos supermercados de menor porte se organizarem no sentido da criação de uma área específica para prevenção de perdas. Entre os principais recursos tecnológicos aplicados à prevenção de perdas, a pesquisa identificou os mais utilizados e sua relevância na utilização no varejo, conforme apresenta a Tabela 1. 
Tabela 1 - Principais recursos tecnológicos aplicados à prevenção de perdas

\begin{tabular}{lcc}
\hline Recurso & Possui & Não \\
\hline CFTV - Circuito fechado de televisão & $87 \%$ & $13 \%$ \\
Uso de coletor de dados p/ realização do inventário & $74 \%$ & $26 \%$ \\
Alarmes de acesso & $71 \%$ & $29 \%$ \\
Rádios comunicadores & $65 \%$ & $35 \%$ \\
Cofre boca-de-lobo & $64 \%$ & $36 \%$ \\
\hline Uso de coletor no recebimento & $64 \%$ & $36 \%$ \\
Solução de Monitoramento de frente de caixa & $41 \%$ \\
Software de monitoramento e acompanhamento das perdas & $59 \%$ & $45 \%$ \\
Espelhos & $55 \%$ & $51 \%$ \\
\hline Controle de acesso eletrônico à área de tesouraria & $49 \%$ & $55 \%$ \\
Cabos, correntes ou dispositivos de fixação de produtos & $45 \%$ & $59 \%$ \\
\hline Lacradoras de sacolas & $41 \%$ & $62 \%$ \\
\hline Caixas acrílicas & $38 \%$ & $63 \%$ \\
\hline Etiqueta antifurto & $37 \%$ & $67 \%$ \\
\hline Cadeados Eletrônicos & $33 \%$ & $87 \%$ \\
\hline
\end{tabular}

Fonte: ABRAS (2015)

Em relação às principais atividades adotadas em relação ao envolvimento das pessoas nos processos de prevenção de perdas, a pesquisa identificou as seguintes atividades mais relevantes, conforme indica a Tabela 2 .

Tabela 2 - Atividades adotadas para prevenção de perdas

\begin{tabular}{lcc}
\hline Atividade & Executa & Não \\
\hline Treinamentos em Prevenção de Perdas para colaboradores & $74 \%$ & $26 \%$ \\
Introdução de processos mais cuidadosos no recrutamento e seleção & $72 \%$ & $28 \%$ \\
jornais/revistas/artigos) & $51 \%$ & $49 \%$ \\
Comunicação de Prevenção de Perdas (mural de avisos, perdas) & $41 \%$ & $59 \%$ \\
Participação nos lucros/remuneração variável atrelada aos resultados de & $39 \%$ & $61 \%$ \\
Telefone de denúncias / informações & $29 \%$ & $71 \%$ \\
Concursos de redução de perdas com premiações & $20 \%$ & $80 \%$ \\
Curso da Escola Nacional de Supermercados de Prevenção de Perdas & $9 \%$ & $91 \%$ \\
\hline Outros & & \\
\hline Fonte: ABRAS (2015) & & $90 \%$
\end{tabular}

Fonte: ABRAS (2015)

A pesquisa ABRAS (2015) identificou os principais processos implantados para reduzir riscos e apoiar a prevenção de perdas. Entre eles, destacam-se os principais relacionados na Tabela 3. 
Tabela 3 - Soluções de controle adotadas

\begin{tabular}{lcc}
\hline Solução & Executa & Não \\
\hline Controle de Troca (Cliente) & $90 \%$ & $10 \%$ \\
Controle detalhado de recebimento & $21 \%$ \\
Checagem do lixo & $79 \%$ & $23 \%$ \\
Auditoria do Inventário & $77 \%$ & $26 \%$ \\
Controles de transferência entre lojas & $74 \%$ & $27 \%$ \\
Auditorias de procedimentos operacionais & $73 \%$ & $29 \%$ \\
Controle de anulados e cancelados & $71 \%$ & $29 \%$ \\
Abordagens Reativas (na saída da loja) & $71 \%$ & $34 \%$ \\
Controle de acesso na portaria de funcionários & $66 \%$ & $43 \%$ \\
Abordagens Preventivas (interior da loja) & $57 \%$ & $43 \%$ \\
Revista na portaria / armários de funcionários & $57 \%$ & $53 \%$ \\
Utilização de saco de lixo transparente & $47 \%$ & $64 \%$ \\
\hline Cliente Misterioso / Oculto & $36 \%$ & $86 \%$ \\
\hline
\end{tabular}

Fonte: ABRAS (2015)

Outra informação bastante relevante da pesquisa mostra que $43 \%$ das empresas que responderam o questionário, o executivo do departamento de prevenção responde diretamente à alta cúpula da corporação, sinalizando a importância desta área, e das atividades do ponto de vista da governança ABRAS (2015). O capítulo seguinte apresenta a metodologia empregada nesta pesquisa.

\section{METODOLOGIA}

A pesquisa se caracteriza como qualitativa, baseada em um estudo de caso único, que segundo o autor Richardson et al. (2007), é um tipo de investigação que se apresenta aderente aos estudos que pretendem explorar problemas complexos, realizar análise de relação entre variáveis, e estabelecer uma classificação para processos dinâmicos. Desta forma, a pesquisa qualitativa se mostrou adequada ao objetivo proposto.

Para o estabelecimento da análise dos fins e meios desta pesquisa, utilizou-se a abordagem proposta por Vergara (2016). Assim, quanto aos fins, a presente pesquisa se posiciona como descritiva, buscou identificar a importância, e a contribuição da Prevenção de Perdas realizada no âmbito da operação de lojas do segmento supermercadista. Quantos aos meios, a pesquisa se caracteriza como um estudo de caso. E estudo de caso único por analisar uma empresa única, mas com várias lojas distribuídas por todo o Brasil. Esta etapa da pesquisa realizou entrevistas com membros da empresa a fim de aprofundar-se na investigação dos procedimentos, protocolos, resultados e interlocução envolvidos no processo de Prevenção de Perdas das operações realizadas pela empresa. Vale destacar, que para Yin (2015) o estudo de caso possibilita um tipo de investigação que nos permite compreender os fenômenos de forma única, condição está presente neste estudo.

Para Vergara (2016) o critério de acessibilidade é valido, e empregado em decorrência da facilidade de acesso aos dados. Por conseguinte, a conveniência e a acessibilidade foram os fatores determinantes para a seleção da empresa investigada. Não obstante, o tipo de informação abordada nesse trabalho recebe tratamento sigiloso nas empresas, condição esta que justifica a adoção de um único caso em análise. Portanto, a abertura para realização dessa 
pesquisa decorreu do aceite e concordância da empresa em fornecer as informações necessárias. O estudo de caso desenvolvido fornecesse informações sobre as práticas de prevenção de perdas que contribuam e agreguem valor à Governança Corporativa - GC da companhia pesquisa.

Apesar do aceite da empresa em disponibilizar as informações necessárias para a realização da pesquisa, a mesma solicitou que não fosse revelado o seu nome, de forma a ser tratada nesse trabalho pelo nome fictício de Empresa de Varejo Supermercadista. A coleta dos dados se pautou em entrevistas com agentes envolvidos no processo de Prevenção de Perdas da empresa pesquisada. Nesse sentido, se utilizou um questionário com perguntas abertas e fechadas. O questionário elaborado foi utilizado como um roteiro de entrevista, com a finalidade de garantir que os pontos de interesse fossem abordados, e o estabelecimento de um padrão homogêneo de entrevista por parte do pesquisado, conforme propõe Vergara (2016). As entrevistas abrangeram funcionários de duas unidades da empresa, e foi realizada com os funcionários dos seguintes cargos: i) Supervisor de Prevenção de Perdas; ii) Coordenador; iii) Chefe de Departamento; iv) Gerente de Loja.

Os entrevistados estão divididos em dois grupos denominados Loja 1 e Loja 2. Esta diferenciação está relacionada ao fato de ter-se entrevistado duas lojas da rede. A Loja 1 situação na cidade de São Paulo e a Loja 2 situada em uma cidade da região do ABC de São Paulo. O número final de entrevistados foi de seis funcionários. Ao final das entrevistas, as respostas foram analisadas. Os pontos principais foram digitados em planilha de Excel. Neste estudo, optou-se por apresentar os dados coletados nas entrevistas na forma de interpretação do que foi relatado pelos entrevistados, e não na simples descrição do áudio. Essa abordagem foi adotada com o intuito de apresentar os dados de forma mais sucinta, pois os relatos apresentaram-se muito longos e com vários vícios de linguagem. Neste capítulo, descreveramse as técnicas empregadas no levantamento dos dados necessários para suportar os objetivos estabelecidos. Os dados levantados estão apresentados no capítulo seguinte.

\section{APRESENTAÇÃO E ANÁLISE DOS DADOS}

Este capitulo inicialmente realiza a apresentação da empresa e na sequencia relatasse os dados obtidos nas entrevistas.

\subsection{EMPRESA PESQUISADA}

A empresa pesquisada, neste estudo, denominada como Empresa de Varejo Supermercadista, possui características bastante marcantes, tanto pelo seu porte quanto por sua trajetória de desenvolvimento. Atuando em todos os estados da federação, com mais de 150 filiais entre lojas de autosserviço e centros de distribuição, estrategicamente localizados, conta com aproximadamente 36 mil colaboradores (dados de 2015). A Empresa de Varejo Supermercadista possui como características operacionais: i) Comercializar produtos do gênero alimentício e bebidas em geral; ii) Seu público alvo é composto de comerciantes, transformadores e público em geral; iii) Ofertar diversidade de itens, disponibilizando mais de dez mil itens em suas prateleiras; iv) Pratica preços menores, para os itens comprados em grande quantidade; v) Venda no atacado.

A empresa iniciou suas atividades na primeira metade dos anos 1960, no estado do Paraná, atuando como representante comercial de gêneros alimentícios. Na década de 1980 a empresa iniciou a sua expansão abrindo lojas em mais seis estados da federação e com a criação de marcas próprias em produtos comercializados apenas em suas unidades. $\mathrm{O}$ acontecimento mais significativo nessa fase, segundo os fundadores, foi a criação do modelo 
de atacado de autosserviço, no qual os clientes podiam comprar os produtos em lotes maiores, e desta forma ter acesso a descontos proporcionais. Na década de 1990 continuou a sua expansão, incentivada estabilidade econômica brasileira. Neste período foram introduzidos novos sistemas de informação integrando as filiais de forma rápida e segura.

No ano de 2007 ocorreu a aquisição de $100 \%$ do capital da empresa por um grupo multinacional com sede na França. Após a aquisição o novo grupo controlador efetuou um expressivo aporte financeiro e direcionou a companhia para a expansão e consolidação dos negócios. No ano de 2015 a empresa apresentou o seguinte desempenho: i) 130 lojas de Autosserviço e 25 Centros de Distribuição; ii) Aproximadamente 36 mil funcionários; iii) Variedade de oferta, com 11 mil itens comercializados; iv) Faturamento de 21 bilhões (2015); v) Índice de perdas em torno de 1\% (2015).

A seção seguinte apresenta os dados coletados nas entrevistas realizadas.

\subsection{DADOS DO SETOR DE PREVENÇÃO DE PERDAS NA EMPRESA}

O primeiro questionamento realizado aos colaboradores que participaram da entrevista foi acerca da existência e estrutura de uma área destinada a Prevenção e Perdas na empresa. O Coordenador de Prevenção de Perdas (Loja 1) explicou que existe uma área de Prevenção de Perdas estruturada na empresa por meio de um núcleo dentro do Departamento de Operações. Este por sua vez, é liderado por dois executivos que se reportam diretamente ao Presidente - CEO e ao Conselho de Administração - CA. O núcleo de Prevenção de Perdas é formado por um Gerente de Operações, Supervisor Geral de Prevenção de Perdas, Coordenador Nacional de Prevenção de Perdas, Analistas de Prevenção de Perdas e vários outros analistas regionais de campo, que dividem entre si as filiais geograficamente. A Prevenção de Perdas tem a função de efetuar o monitoramento e controle das atividades corporativas dadas às possibilidades de perdas nos âmbitos financeiros, fiscais, jurídicos, de ruptura e em especial das quebras operacionais. Entre os principais motivos das quebras operacionais, estão as avarias causadas nas mercadorias por movimentação e acondicionamentos inadequados, prazos de validade expirados, deterioração dos perecíveis. Com essa perspectiva a pesquisa buscou identificar as práticas adotadas para evitar as quebras operacionais.

Segundo o Coordenador de Prevenção de Perdas (Loja 2), todas as quebras são identificadas e mapeadas. Relatórios diários são gerados pelos sistemas de informação da companhia, divulgados e analisados no intuito de estabelecer medidas para inibir ou estancar as ocorrências. O entrevistado acrescenta que a visão tradicional de prevenir perdas orientada especificamente para a vigilância da loja não é suficiente para surtir os efeitos esperados. $\mathrm{O}$ Supervisor de Prevenção de Perdas (Loja 2) acrescenta que é função da área de Prevenção de Perdas realizar processos de identificação, mitigação e respostas a riscos, contanto inclusive como um canal direto de comunicação com a alta gestão. Nesse sentido, ele acrescentou que dispõe de uma base de dados para tomada de decisões. Segundo o colaborador a empresa possui um sistema de informações integrado que mantém acompanhamento e controle dos processos do negócio, incluindo o controle de quebras. Esse sistema abrange os itens transporte, recebimento de mercadorias, estoque e armazenamento, área de vendas (exposição) e frente de caixa, gerando relatórios diários que servem de suporte para acompanhar, identificar e gerar conhecimento sobre eventuais ocorrências de quebras operacionais.

Todos os entrevistados relataram que grande parte das quebras ocorre no transporte, armazenamento e acondicionamento das mercadorias. Entretanto, destacam que é 
fundamental a organização da área de recebimento para evitar que cargas recebidas sejam avariadas, ou que fechem a circulação de pessoas e equipamentos permitindo que mercadorias permaneçam mais tempo do que o necessário fora das condições ideais ou sujeitas a impactos e perdas. A realização dessas tarefas está descrita nos manuais de normas e procedimentos e deve ser seguida pelas equipes com monitoramento e auditoria frequentes (Gerente Loja 2). O Coordenador de Prevenção de Perdas (Loja 1) destaca que o transporte é realizado dentro dos padrões de segurança necessários, e são respeitados, o espaço útil, a capacidade dos veículos, o tamanho da carga, o peso, o acondicionamento adequado, e os cuidados especiais destinados a cargas sensíveis. Ao serem retiradas, as cargas são transferidas para docas adequadas ao tipo de mercadoria (Coordenador de Prevenção de Perdas, Loja 1). As áreas de descarga são preparadas de modo a reduzir ao máximo os impactos sobre as mercadorias, e facilitar a movimentação até o respectivo local de guarda. Os itens resfriados ou congelados recebem tratamento específico em ambientes com temperaturas adequadas e têm prioridade sobre outras cargas (Chefe de Departamento, Loja 1).

No recebimento de mercadorias se verifica a existência de pedido do item junto a aquele fornecedor e processa-se a conferência da nota fiscal, que deve estar coerente com o pedido e com a carga entregue. Na sequência, se realiza a conferência física nos lotes para certificar que não há faltas ocultadas ou avarias das mercadorias. Em caso de identificação de anomalias, o comprador (responsável) é notificado para gerenciar a situação e tomar decisão sobre a procedência do recebimento. No caso de se identificar inconsistências, pôde-se tomar uma das seguintes medidas: - Devolução de toda a carga; - Realizar ajustes no pedido, adequando-o a condição real; - Emitir nota fiscal de restituição de valor para ajustar a entrega com o pedido. (Supervisor de Prevenção de Perdas, Loja 1). Semanalmente são realizados mutirões de mobilização para identificação de desvios, erros ou fraudes. Em alguns mutirões, são abertos todos os paletes e/ou caixas de mercadorias para checar se as quantidades de itens por embalagem estão corretas. Em outras, os paletes e/ou caixas são pesados para verificação se o peso está de acordo com as especificações do fornecedor, ou dos documentos fiscais. Estes mutirões são realizados, também nas áreas de transporte, armazenagem, exposição e bateria de caixas (Supervisor de Prevenção de Perdas, Loja 2).

O Gerente de Loja (Loja 2) informa ainda, que a área de recebimento realiza uma verificação bastante minuciosa para identificar se há mercadorias danificadas, violadas ou faltantes, nos lotes entregues. Para tais eventualidades inconsistências é possível definir em conjunto com a área comercial da companhia como proceder com o lote, optando-se pelo não recebimento do lote devolvendo produtos envolvidos. A execução sistemática desses procedimentos inibe que fraudes sejam orquestradas por terceiros, que por ventura, tenham observado displicência na conferência. $O$ conferente não tem ciência sobre as quantidades acordadas no pedido de compras, o entregador acompanha essa conferência, processo este denominado como conferencia cega, pois o conferente não sabe qual é a quantidade de itens que ele está analisando (Gerente de Loja, Loja 2).

No armazenamento, dos itens adquiridos, considera-se as recomendações do fornecedor sobre empilhamento, temperatura, tipo de acondicionamento. $\mathrm{Na}$ exposição devem ser tomados os mesmos cuidados em relação a empilhamento, temperatura, adicionando a isso cuidados com o tamanho, leiaute e alinhamento da exposição caixa (Coordenador de Prevenção de Perdas, Loja 1). Segundo o Supervisor de Prevenção de Perdas (Loja 1) o inventário é uma das ferramentas mais importantes na identificação de pontos vulneráveis na operação, e geração de quebras operacionais. O inventário tem a característica de ser diário e rotativo, ou seja, todos os dias são contados alguns setores de mercadorias. Esse processo diário expõe os dois principais tipos de perdas: as conhecidas e as desconhecidas. A perdas 
conhecidas são aquelas que indicam diretamente a origem da ocorrência e logo, as equipes responsáveis são comunicadas para tomar providências. Além das quebras operacionais, as perdas de estoque também são provenientes de outras fontes. Entre elas destacam-se os furtos externos e furtos internos. Estes entrevistados relataram que aos furtos externos, emprega-se práticas de abordagens preventivas, câmeras de filmagem, e forte fiscalização na frente de caixa, e na saída da loja. Adota-se a mesma abordagem na prevenção dos furtos internos, adicionando-se ações de verificação de acesso e saída de funcionários e terceiros. Para evitar erros administrativos, a organização do estoque é fundamental para que mercadorias não fiquem "perdidas" no depósito ou em áreas das quais não pertençam. Durante os inventários, as contagens são repetidas até três vezes para evitar erros (Coordenador de Prevenção e Perdas, Loja 1). De acordo com o Supervisor de Prevenção de Perdas (Loja 2), os colaboradores da segurança patrimonial, apoiados por sistema de câmeras de filmagem, se encarregam do monitoramento de clientes em ação suspeita, e da realização de abordagens preventivas no interior da loja ou mesmo de forma reativa do lado de fora.

O Gerente de Loja (loja 2) detalhou algumas tarefas realizadas visando a redução de furtos. Segundo ele os procedimentos são: - Controle de entrada e saída de pessoas; - Cadastro de prestadores de serviço; - Fiscalização ao patrimônio; - Controle de lacres de portas; Controle de chaves; - Gerenciamento de ocorrências internas e externas; - Acompanhamento ao sistema de monitoramento; - Auditoria ao depósito; - Controle do PAR (produto alto risco); - Auditoria das cargas recebidas; - Preenchimento de controle de acesso de caminhões; - Ficha de entrada e saída de produtos do setor de confinados; - Organização do setor de confinados; - Troca de senha nos sistemas; - Segregação de funcionalidades no sistema, - Liberação de cigarros e produtos de alto risco; - Controle de correspondências da unidade; e - Abordagem de pessoas em atitudes suspeitas.

O Coordenador de Prevenção de Perdas (loja 2) aponta que os caixas recebem treinamentos destinados a auxiliar como se identifica cédulas falsas, e como evitar possíveis golpes. Este treinamento se apoia em problemas em grande parte identificados e mapeados. Os caixas recebem alertas, via sistema, quando o limite de numerário no caixa e ultrapassado. Quando da ocorrência deste problema, o operador de caixa é instruído a realizar sangrias (retirada de excesso de numerário) imediatamente. Assim o procedimento de coleta e guarda de numerário é realizado toda vez que necessário, com a transferência ao cofre, que por sua vez também possui alerta, quando se supera os limites estipulados, o carro-forte é acionado para recolher o excedente.

Apesar das abordagens preventivas em relação às perdas de estoque e financeiras, as perdas administrativas, também exercem grande pressão para impulsionar os índices das empresas. Esses eventos são monitorados pelos fiscais de perdas e possuem um forte auxilio da tecnologia para automatizar e gerir os recursos como telefone, luz, água, internet. Outras abordagens para redução de perdas por falhas administrativas são incorporadas ao processo. Como exemplo o Coordenador de Prevenção e Perdas (Loja 2) destaca o chamado "papa-fila" que tem por objetivo agilizar as operações na frente de caixa reduzindo o tempo do cliente na fila em até $30 \%$, por meio da antecipando a leitura digital, ainda na fila, das mercadorias separadas para compra. Apoio ao cliente para tirar dúvidas sobre mercadorias e disponibilidade oferecido por meio da utilização de aparelhos portáteis de consulta ao estoque pode ser encontrado nos corredores em poder de funcionários específicos para tal função. $\mathrm{Na}$ perspectiva de perdas de recursos como água, luz e energia, a Prevenção de Perdas desenvolve um trabalho da equipe de comunicação no sentido de conscientizar os colaboradores com programas específicos, palestras, comunicação institucional e divulgação de resultados para criar um envolvimento com a causa. Outros mecanismos ligados à tecnologia também são 
utilizados tais como: redução do uso de relatórios impressos, e apoio à utilização de arquivos digitais. Nas abordagens ligadas a melhoria do atendimento, um importante processo denominado "papa-fila" ajuda a reduzir as filas e o tempo de atendimento com a utilização de coletores de dados enquanto o cliente aguarda, antecipando o trabalho do operador de caixa (Supervisor de Prevenção de Perdas, 2016).

Perdas administrativas geralmente decorrem de erros operacionais, como: - Entrada de produto equivocada: - Erros na conferência; - Furto interno e externo e; - Falta de organização do estoque. As perdas administrativas estão ligadas diretamente as ações dos colaboradores, com destaque para: - Economia de água, economia de energia; - Perda de uniforme ou mau uso dos mesmos; - Depredação do patrimônio; - Uso inadequado de equipamentos da loja gerando manutenção constante e aumento dos gastos (Gerente de Loja, Loja 2). Para este gerente de Controles Internos, "Busca-se a identificação dos motivos das perdas e se gera medidas para se eliminar ou reduzir esses motivos. Há acompanhamentos para se identificar as principais causas, para que se tomem as medidas necessárias para evitar ou reduzir a perda".

O Gerente de Loja (Loja 2) complementa, suas ponderações, explanando sobre a aplicação de meios tecnológicos, motivacionais e de processos realizados na companhia. Segundo ele, são implementados controles e automatização de recursos como água, energia elétrica e telefone. Um trabalho bastante intenso de conscientização utilizando recursos como cartazes educacionais também é realizado para reduzir as perdas dos recursos citados. $\mathrm{Na}$ questão de perdas relativas a ineficiência de processos de venda, são utilizados recursos como "caixa rápido" e caixas para atendimento especial conforme solicita a legislação.

A Ruptura no varejo é uma ocorrência geradora de perdas significativas para uma empresa, em especial, para aquelas que atuam no modelo de autosserviço conforme destacou o Coordenador de Prevenção de Perdas (2016). Para este funcionário houve, naempresas, um grande investimento em tecnologia para evitar e reduzir a ruptura. Segundo ele, um sistema informatizado monitora em tempo real os estoques informando para os estoquistas e repositores os locais de exposição que necessitam reabastecimento. Essa comunicação se dá por meio de aparelho digital portado por cada um dos participantes do processo. Além da comunicação e solicitações de reabastecimento, o sistema ajuda a identificar preços incorretos, mercadorias fora da área de vendas e facilita a consulta de informações e atendimento ao cliente. Do ponto de vista da reposição de mercadorias junto ao fornecedor, o sistema de informações ajuda a identificar estoques em seu nível mínimo e, com base em curvas de demanda e outros indicadores, orienta os compradores a realizar novos pedidos. Esses pedidos são acompanhados em toda a cadeia até o recebimento na loja (Coordenador de Prevenção e Perdas, Loja 1).

Já o Supervisor de Prevenção de Perdas (Loja 2) separa a Ruptura em dois planos: A ruptura comercial, e a ruptura operacional. No primeiro caso, um trabalho dos compradores apoiado por um sistema de informações aponta diariamente as mercadorias que devem ser reabastecidas. Feito isso, um gerenciamento e acompanhamento dos pedidos é realizado até o momento do recebimento das mercadorias. A área comercial realiza esses procedimentos, mas a gerência da loja tem ciência de todo o processo, e o acompanha via sistema. Feito o recebimento, várias ferramentas e processos são utilizados para que a mercadoria esteja sempre disponível na gôndola para venda. Entre elas, a utilização de um sistema de monitoramento de movimentação de mercadorias e de coletores de dados que auxiliam no trabalho de reposição, informando aos repositores por meio de mensagens digitais, quais mercadorias, em qual setor, devem ser repostas. Em outro espectro, as mercadorias devem ser recebidas de forma adequada e com segurança, armazenadas nos lugares corretos e de fácil

Revista ENIAC Pesquisa, Guarulhos (SP), V.6, n.2, jun.- dez. 2017 
recuperação, evitando obstrução do depósito para a boa fluência do tráfego. Pessoas capacitadas devem realizar o abastecimento da mercadoria na gôndola, sendo que esses eventos são monitorados com o objetivo de reduzir essas ocorrências.

O Gerente de Loja (Loja 1) aponta as razões pelas quais a operação se depara com a Ruptura. Ele lembra que a loja possui diversos relatórios que identificam as rupturas e que podem ser causadas por diversos fatores: Falta de produto - quando existe a ruptura por falta de produto o departamento de compras é acionado para que supra a falta do produto o mais breve possível, evitando a perda de venda; Produto em estoque: produtos armazenados no estoque, mas que por alguma ineficiência na operação não estão expostos na gôndola. Falta de espaço: Dificuldade no recebimento por falta de espaço para armazenamento. O Chefe de Departamento (Loja 1) sinaliza a importância do uso de tecnologia na redução da incidência de Ruptura na área de vendas. Segundo ele, há na empresa um sistema de reposição de mercadorias baseado em uma moderna tecnologia instalada para executar esse trabalho com eficiência. Os repositores têm à sua disposição um aparelho de sinal digital no qual recebem as tarefas de ressuprimento indicando as mercadorias e os locais que devem ser reabastecidos. Esse mesmo sistema auxilia na identificação de preços incorretos, localização da mercadoria e consultas de preço e estoque em tempo real.

A entrevista se encerravam com a solicitação para que aos entrevistados explanarem sobre o tema gerenciamento de crise, e plano de contingência. Com destaque para este questionamento identificou-se os seguintes estaques. O Coordenador de Prevenção de Perdas (Loja 1) afirmou que "(...) a empresa possui um plano de gerenciamento de crise. Para cada evento existe uma abordagem de ação e comunicação dentro da empresa", enquanto que o Supervisor de Prevenção de Perdas (Loja 2) esclarece que um manual de gerenciamento de risco foi desenvolvido abordando desde as situações mais corriqueiras do dia-a-dia da operação de uma loja, até os casos mais extremos como incêndios, enchentes passando por acidentes, até greve de empresas transportadoras de numerário, greve de funcionários, sindicatos, órgãos fiscalizador, designando quais ações devem ser tomadas e quais áreas ou pessoas devem ser comunicadas. Os gerentes ficam de posse desse manual que funciona como uma referência na qual são determinados todos os procedimentos a serem realizados em caso de crise.

As limitações da presente pesquisa dizem respeito aos seguintes aspectos: i) todo o monitoramento e auditoria de processos relatados e analisados, dizem respeito somente àqueles que têm a área de Prevenção de Perdas como ator interessado no desempenho e controle dos procedimentos auditados, ii) por tratar-se de um estudo de caso único no qual a empresa pesquisada possui características, recursos e cultura muito peculiar, torna-se inviável realizar generalizações diretas dos resultados obtidos para todas as empresas de varejo supermercadista. No entanto, é possível inferir que partes expressivas das informações abordadas por essa pesquisa podem servir de referência para as práticas de prevenção de perdas adotadas em outras companhias do setor. Por sua vez, a adoção dessas práticas poderia agregar contribuições significativas para a governança das respectivas empresas.

Frente aos dados obtidos na pesquisa, e ao referencial elaborado em capitulo anterior, o capítulo seguinte desenvolve a discussão.

\section{DISCUSSÃO}

Este capitulo se destina a analisar os dados obtidos na investigação, frente ao referencial teórico estabelecido para suportar o estudo. Os dados apontam que na loja de varejo pesquisada, há a preocupação com a gestão de riscos e prevenção de perdas. A abordagem da

Revista ENIAC Pesquisa, Guarulhos (SP), V.6, n.2, jun.- dez. 2017 
empresa se posiciona dentro do cenário apontado por Piotto, Fávero e Angelo (2004), no qual se identifica a crescente preocupação com as perdas, e com esforços destinados a sua mitigação nas empresas varejistas, em especial, no segmento supermercadista. A atenção da empresa para com as perdas destina-se ao aumento de sua margem de lucro, condição está adequada segundo as indicações de Gomes, González Júnior e Lorett (2010) que indicam que perdas são ocorrências, que necessariamente reduzem os lucros provenientes da operação da loja.

A empresa apresenta uma linha de comando e de informações destinadas a gestão dos riscos operacionais. Esta estrutura é formal é hierárquica com responsabilidades e funções definidas. A organização da empresa se posiciona de forma similar com os resultados identificados por Moura (2014) em que grandes companhias já possuem um setor específico de Prevenção de Perdas, e o executivo do departamento de gestão de riscos, respondendo diretamente à alta cúpula da corporação. Reforçando assim, a importância da área de riscos nas atividades da empresa. O fluxo de informações para o mais alto nível da empresa, associado a análise e planejamento de ações por este nível da empresa, o contextualiza dentro do escopo da Governança Corporativa, pois os resultados positivos, possuem ligação estrita com a geração de lucro da empresa, e por consequência de interesse para os acionistas e seus representantes no Conselho de Administração. Vale destacar, que esta abordagem de gestão dos riscos operacionais esta consonante, com a posição da ABRAS (2015) que frente à importância do setor varejista, para o mercado de consumo e para a economia em geral, e ainda pelas vulnerabilidades existentes na cadeia produtiva e na operação do setor, os esforços destinados a redução de perdas, são positivos para a sociedade como um todo.

Identifica-se na empresa analisada, uma robusta estrutura, com quatro níveis de atuação, envolvidos no gerenciamento dos riscos operacionais, e abarcados por uma estratégia definida pelo nível que contém os executivos responsáveis pela gestão da empresa. Este posicionamento se alinha com a abordagem de Santos (2007), em que a prevenção de perdas passou a ser tratada como metodologia, e área de trabalho, de vital importância para o resultado da empresa. Ainda segundo o autor, neste contexto, as atividades voltadas a mitigação dos riscos e das perdas não são interpretadas como custos adicionais, mas sim como investimentos que otimizam o lucro das empresas. A ABRAS (2015) e Moura (2014), destacam que o monitoramento permanente dos riscos por meio das atividades diárias de Prevenção de Perdas, com a participação da alta administração no planejamento das estratégias preventivas, estabelecendo metas anuais e mensais, bem como metas gerais e por unidades de negócio, proporcionam melhor desempenho para a empresa. Adicionalmente Moura (2014) que a prevenção de perdas exige planejamento estratégico de longo prazo e participação de todos os atores da empresa, com a realizando ações de curto, médio e longo prazo.

A abordagem de risco operacional do Banco Central (2006) que associa o resultado das operações da empresa, aos controles internos realizados, que se apresenta consonante a proposição do Bank for International Settlements (BIS, 2004, p. 12) em que “(...) o risco operacional é definido como o risco de perda resultante de processos internos, sistemas inadequados, eventos externos e pessoas. Essa definição inclui o risco jurídico, porém exclui o estratégico e de reputação". Indicam a importância das pessoas, e dos controles executados pelas empresas na gestão do risco operacional. Adicionalmente Hahn e Kuhn (2012) enfatiza a importância de uma adequada gestão do risco operacional, destinada a identificar solucionar problemas relacionados a: - processos de negócio inadequados ou deficientes; - falhas nos controles internos; - falhas de treinamento das pessoas que operam esses processos e; inadequação de ferramentas, métodos, procedimentos e sistemas empregados na operação. As 
entrevistas realizadas indicam que a empresa se utiliza de ferramentas de monitoramento, controle e auditoria dos processos de negócio e está estruturada sobre as normas e procedimentos definidos para cada atividade. Com base nesse monitoramento, são geradas informações acerca do desempenho, sucesso e falhas dos processos, sendo que essas informações são analisadas dentro de um processo de acompanhamento que inclui: a área de Prevenção de Perdas, a Alta Gestão e outros interessados. Assim, as práticas evidenciadas na empresa se posicionam harmoniosas com as proposições dos autores.

A falta de padronização de procedimentos é fator que corrobora para o insucesso da execução da estratégia corporativa, e o alcance de metas, fomento assim o risco operacional (TEIXEIRA NETO; ARAÚJO, 2007). Na empresa estudada observou-se padronização na gestão dos riscos, as duas unidades analisadas apresentaram a execução de suas atividades em aderência aos padrões estipulados. Adicionalmente, observa-se entre os funcionários envolvidos o entendimento da necessidade de realizarem os procedimentos de forma aderente aos padrões estabelecidos nos protocolos da empresa. Esta maior conscientização dos funcionários se posiciona como um fator positivo conforme destaca Longo (2009). O autor aponta que, o aumento da conscientização contribui para a redução a exposição dos riscos operacionais.

Associada a conscientização dos funcionários, Lunkes (2010) indica a importância de ações de treinamento e reciclagem dos funcionários, como fator de redução de ações de desperdício, e por consequência de mitigação de riscos. Observou-se nas entrevistas realizadas a existência de ações de treinamento e reciclagem, destinadas ao aprimoramento dos funcionários, e consolidação dos procedimentos existentes. Dentre os treinamentos realizados, os colaboradores destacaram o executado para as equipes de frente de caixa, que colabora na identificação e prevenção de possíveis golpes, fraudes, cédulas falsas entre outros eventos. Para os funcionários a cada treinamento é possível aprender os novos golpes que estão sendo aplicados contra a empresa.

Como destacado anteriormente, quebras operacionais, em grande parte, são as avarias causadas nas mercadorias por movimentação e acondicionamento inadequados, que reduzem o valor comercial, parcial ou total. Também são consideradas quebras operacionais prazos de validade expirados, deterioração dos perecíveis e degustação de produtos com suas embalagens de origem (SANTOS, 2007). Observou-se nos depoimentos dos entrevistados, que os sistemas de informação possuem importante papel nos processos de apuração das quebras operacionais, com o processo fortemente pautado na execução das atividades descritas sob as normas e procedimentos. Identificou-se que as bases de dados históricos da empresa, elaboradas mediante a informações decorrentes da execução das operações, e seus os registros de transações em tempo real, estabelecem um histórico, que auxilia na avaliação e monitoramento das perdas, possibilitando a gestão dos riscos.

Conforme postulado por Santos (2007), entre as principais causas de quebras operacionais originárias no recebimento e destinação de mercadorias, figuram: i) Transporte; ii) Recebimento de Mercadorias; iii) Estoque e Armazenamento; iv) Exposição. Observou-se que, para cada uma dessas causas, a empresa adota um procedimento no sentido de minimizar ocorrências e/ou o impacto de eventos geradores de perdas nessas áreas. Santos (2007), destaca que a mitigação destas ocorrências demanda a realização de ações preventivas orientadas à manutenção dos estoques. Essas ações têm por objetivo evitar: i) furto externo; ii) furto interno; iii) erros administrativos nos registros de estoques; iv) fraude de terceiros. Entre as práticas mais expressivas, observadas nos relatos dos entrevistados, se evidenciou a preocupação com a adoção de padrões de transporte no que diz respeito às características do

Revista ENIAC Pesquisa, Guarulhos (SP), V.6, n.2, jun.- dez. 2017 
veículo, ao tipo, peso, volume, temperatura no sentido de dar proteção e segurança às cargas, e a adequação dos locais de descarga, que devem estar adaptados às especificações de veículos e formatos de cargas. Os entrevistados relataram que a conferência sistemática das mercadorias recebidas é bastante importante para evitar possíveis fraudes e quebras de estoque. Esse trabalho consiste em identificar, possíveis inconsistências entre pedido de compra e nota fiscal dos produtos entregues. A conferência conta com recursos de sistemas de informação e tecnologia para aumentar a produtividade. Para garantir a segurança da operação, essa conferência é realizada por um colaborador que não tem conhecimento dos registros fiscais e administrativos, sendo que a presença do responsável pela entrega para certificar a conferência é mandatória. Esta diversidade de riscos e via ao encontro da abordagem de Bergamini Júnior (2005) de que a classificação dos riscos operacionais é extensa. $\mathrm{O}$ autor destaca, que a eventual não ocorrência de alguns tipos de riscos operacionais, ao longo do tempo, dificulta a utilização de instrumentos de medida e apuração de estatísticas com base na distribuição de frequência.

As respostas evidenciaram preocupação com o bom uso dos recursos, porém, esta pesquisa não se aprofundou em aspectos geradores de retrabalho como as falhas administrativas por erro na utilização de recursos, realização de operações indevidas e inserção de dados incorretos. O não aprofundamento na possível fonte geradora do risco, está relacionada a fota da mesma não pertencer ao objetivo desta pesquisa. Essa ações e estratégias de prevenção implementadas na companhia, conforme evidenciado nos relatos, compactua com as instruções de Santos (2007) descritas em seu manual de prevenção de perdas e gerenciamento de riscos. Segundo o autor estratégias que atuem precisamente em cada um desses pontos destacados, no conjunto, propiciará grande resultado na redução das perdas. $\mathrm{O}$ autor reafirma a importância do monitoramento contínuo e gerenciamento das ocorrências de risco, bem como ações preventivas necessárias.

A discussão dos dados realizada frente ao referencial teórico, possibilita a execução do capítulo seguinte, no qual desenvolve-se as considerações finais.

\section{CONSIDERAÇÕES FINAIS}

Observou-se que a área de Prevenção de Perdas exerce grande influência nas atividades operacionais da operação no setor supermercadista. A atuação da área de prevenção de perdas contribui no resultado financeiro do setor. A análise realizada possibilitou identificar um conjunto de práticas destinadas a prevenção de perdas no setor de varejo supermercadista.

As práticas de prevenção de perdas apresentam, em grande parte, sinergia potencializando assim os resultados positivos. A existência de uma estrutura organizacional voltada a atividade de prevenção de perdas, com cargos definidos se apresenta como uma pratica apropriada, pois desta forma há o entendimento dos envolvidos, de suas atribuições e responsabilidades. A existência desta estrutura favorece o processo de comunicação, e fluxo de informação, entre a alta gestão e o pessoal de operação no piso da Loja. Comunicação esta que não se limita ao nível transversal da empresa, ela também ocorre de forma longitudinal, ou seja, entre as diversas unidades da empresa. Assim, problemas identificados em uma loja podem ser compartilhados com as demais, evitando assim a ocorrência destes. A estrutura estabelecida na empresa incentiva e facilita este processo de comunicação entre as unidades.

A existência de procedimentos e protocolos de atuação destinados a prevenção deperdas também se posiciona como uma boa pratica do setor de varejo supermercadista, pois 
uniformiza a atuação de todos os funcionários, independentemente do setor, ou da unidade de atuação. Estes procedimentos apresentam ainda os monitoramentos a serem realizados, bem como as metas a serem atendidas. A padronização do monitoramento, e as respectivas metas propostas, favorece a comparação entre as unidades, desta forma é possível identificar desvios de performance e realizar ações de ajustes, ao longo do período. Este processo se otimiza em decorrência da execução de auditorias no sistema. Estas auditorias auxiliam no processo de análise de desempenho, e fornecem robustez a prevenção de perdas da empresa.

A acuidade do sistema e favorecida pelo contínuo processo de treinamento e reciclagem dos funcionários, que para a execução de suas atividades contam com um sistema de informação computadorizado e atualizado instantaneamente. Assim, funcionários treinados com sistema de informações atualizados, possuem condições de executarem uma gestão de prevenção de perdas eficaz.

Frente aos resultados encontrados, emana interesse em identificar se as práticas desta empresa varejista supermercadista, possuem similaridade com as demais empresas que atuam no setor, estabelecendo assim possibilidade de estudos futuros, que consubstanciados a este estabeleceriam o panorama brasileiro do setor de varejo supermercadista.

\section{REFERÊNCIAS}

ASSOCIAÇÃO BRASILEIRA DE SUPERMERCADOS - ABRAS. SuperHiper. Disponível em: <http://www.abrasnet.com.br/abras/>. Acesso em: 17 abr. 2017.

BANCO CENTRAL. Resolução 3.380 de junho de 2006. Disponível em: $<$ https://www3.bcb.gov.br/normativo/detalharNormativo.do? $\mathrm{N}=106196825 \&$ method=detalh arNormativo>. Acesso em: 23 abr. 2017.

BANK FOR INTERNATIONAL SETTLEMENTS - BIS. Convergência internacional de mensuração de capital e padrões de capital - estrutura revisada. Comitê da Basiléia Sobre Supervisão Bancária. 2004.

BERGAMINI JÚNIOR, S. Controles internos como instrumento de governança corporativa. Revista do BNDS, v. 12, n. 24, p. 149-188, 2005.

GOMES, E. G.; GONZÁLEZ JÚNIOR, I. P.; LORETT, R. O surgimento da prevenção de perdas nos supermercados do Brasil. Revista de Administração, v. 1, n. 1, p. 123-133, 2010 .

HAHN, G. J.; KUHN, H. Value-based performance and risk management in supply chains: A robust optimization approach. Inter. Journal of Production Economics, v. 139, p. 135$144,2012$.

LONGO, Eduardo. The knowledge management role in mitigating operational risk. In: Proceedings of the European Conference on Intellectual Capital, In Holland University of Applied Sciences, Haarlem, The Netherlands 28. 2009. p. 314

MERLO, E. M.; CERIBELI, H. B.; DO PRADO, L. S. Gestão de perdas no pequeno varejo: um estudo de caso de uma rede de compras formada por pequenos supermercadistas.

Revista de Administração da Unimep, v. 9, n. 3, p. 40-60, 2011. 
MOURA, G. Manual de Prevenção de Perdas: e sua aplicação estratégica no varejo. 2014. 117p. Disponível em: <https://pt.slideshare.net/gilsonmoura7/boneco-do-livrocorrigido $>$. Acesso em: 23 abr. 2017.

PIOTTO, R. L.; FÁVERO, L. P. L.; ANGELO, C. F. O Perfil das Perdas no Varejo no Brasil e nos EUA: Estratégias e Implicações. In: Seminários em Administração, 7, 2004, São Paulo. Anais... São Paulo: USP, 2004.

RICHARDSON, R. J. et al. Pesquisa social: métodos e técnicas. 3. ed., São Paulo: Atlas, 2007.

SANTOS, C. E. Manual de Planejamento: Prevenção de Perdas e Gestão de Riscos. São Paulo: Editora Sicurezza, 2007. 153p.

TEIXEIRA NETO, O. A.; ARAÚJO, V. P. de. Implementando um modelo de gerenciamento corporativo de riscos em sistemas de transporte de passageiros sobre trilhos. 2007. Disponível em:

$<$ http://www.ferrovia.com.br/arquivos/artigos/gerenciamento_riscos_jun07.pdf $>$. Acesso em: 14 mai. 2016

VERGARA, S. C. Projetos e relatórios de pesquisa em administração. 16 ed. São Paulo: Atlas, 2016.

VIEIRA, José Geraldo Vidal et al. Um estudo exploratório sobre colaboração logística num grande varejo supermercadista. Revista Produção, v. 20, n. 1, p. 135-147, 2010.

YIN, R. K. Estudo de Caso: planejamento e métodos. 5. ed., São Paulo: Bookman, 2015. 